Brief Report

\title{
Misuse (and abuse?) of the concept of empowerment. The case of online offer of predictive direct-to-consumer genetic tests
}

\author{
Loredana Covolo, ${ }^{1}$ Sara Rubinelli, ${ }^{2}$ Grazia Orizio, ${ }^{1}$ Umberto Gelatti ${ }^{1}$ \\ 1Section of Hygiene, Epidemiology and Public Health, University of Brescia, Italy \\ 2Department of Health Sciences and Health Policy, University of Lucerne and Swiss Paraplegic \\ Research, Switzerland
}

Significance for public health

By conducting a content analysis of websites offering DTC susceptibility genetic tests, this study aims to offer a critical contribution to the debate regarding the possible implications on public health of this type of test. Impact on the demand for healthcare services could be possible due to the lack of adequate and regular genetic counselling and difficulty in interpreting the significance of test results. Misuse of the concept of empowerment associated with emphasis on the role of genetic profile in the development of a disease could lead to a misunderstanding of how prevention should be carried out. It is therefore important to underline the need to improve the ability of potential consumers to select the right information, assess it critically and apply it optimally in the context of individual health promotion.

\begin{abstract}
Using the field of direct-to-consumer genetic tests as a case in point, this paper argues against the misuse of the term empowerment, and calls for a regulation of its usage. The misleading assumption under certain current usages of the concept of empowerment is that it is enhanced by the provision of health information. While the information-empowerment correlation is misleading, if not wrong, the feeling of being empowered imposes an increasing burden of critical thinking on those people (patients and consumers) who have to evaluate that information and act for the benefit of their health.
\end{abstract}

\section{Introduction}

As far as the healthcare field is concerned, we live nowadays an age characterized by the ideology of empowerment. Empowerment, conceived both as an outcome and as a process, refers to the acquisition of knowledge and skills to master our own health, and to act in decision-making that is beneficial for the enhancement of our health. ${ }^{1}$

As a reflection of this claim of empowerment, we also live in the socalled information age, which is more or less implicitly characterized by the idea that the empowerment of patients and consumers is enhanced by the provision of health information. The more information about health-related topics people receive, the more effective players they become in the critical thinking process leading to health decisions. ${ }^{2}$

This, for example, is the main argument put forward by the advertisers of prescription medicines or Direct-To-Consumer (DTC) Advertising. As they claim, pharmaceutical companies have more accurate, balanced and scientifically-based information than any other sources. As such, they are in an exclusive position to provide people with adequate information on the safe use of medication, and to create effective knowledge for evaluating the benefits and risks of drug products, and generally in helping people manage their health autonomously. ${ }^{3}$

Assuming the information-empowerment correlation, however, is misleading, if not wrong. As Schulz and Nakamoto claim, ${ }^{4}$ the utility of health information depends on the recipient's background skills in making effective use of that information. One of the key mediators between information and empowerment is people's health literacy. Health literacy, in its comprehensive meaning, includes - alongside traditional reading and numeracy skills - the ability to select the right information, assess it critically and optimally apply it in the context of individual life and existence. ${ }^{5,6} \mathrm{So}$, in order to make sense of the claim Medicine $X$ is used by millions with disease $Y$, which is often found in DTC adverts, consumers must be skillful in finding the potential fallacy known as hasty generalization: although a treatment is used by $\mathrm{X}$ people, how many of them get better? And even if it's a lot, it might still not be good for me. The risk of not thinking that critically is that consumers might overestimate the benefits of a medicine and ignore all the negative consequences. ${ }^{3}$

By drawing from the field of online selling of genetic tests, this paper shows that online health marketing (intentionally or unintentionally, but explicitly) uses the concept of empowerment to market products, and concludes that there is the need for re-calibration of the use of this concept at the policy level.

\section{Materials and Methods}

A systematic World Wide Web search was carried out using the Google and Yahoo! search engines to identify websites that sell genetic tests DTC. To identify other websites of interest, a bibliographical search was conducted on PubMed. Genetic testing was categorized as non-health-related when websites offered parentage confirmation, identity testing, genealogy testing, DNA banking and genetic matching, and health-related when they offered genetic information related to a consumer's current or future health status. We only selected websites selling health-related tests, including ones for predicting susceptibility to future disease or diet-related disease (susceptibility genetic testing/nutrigenetics), and for predicting how individuals may respond to a particular drug treatment (pharmacogenetic tests) (Figure 1).

Sites were excluded if: i) they offered a service that was only available to physicians or for clinical laboratory use; ii) they only sold nonhealth-related genetic tests; iii) they did not sell online; and iv) they required a medical prescription in order to buy the test.

The selected websites were coded using an ad hoc codebook and the content categories were analysed according to the Content Analysis method $^{7}$ in January 2011. In addition to other characteristics, the analysis focused on the types of genetic test, the related information 
and the types of offer, including the selling arguments, namely the statements displayed by the websites to encourage users to purchase tests.

\section{Results}

A total of 30 websites offering DTC genetic testing were found (Appendix Table 1).

Genetic tests for susceptibility to cardiovascular disease were the most frequent on offer (63\%), as shown in Figure 2.

Seventy percent of the websites clearly stated that susceptibility genetic testing was not aimed at diagnosing disease. The purpose of testing declared by the companies emphasized the risk assessment in the majority of them (50\%) in addition to genetic predisposition to developing a disease ( $43 \%$ of the websites). Thirty percent of the websites highlighted the issue of prevention.

Consumers would receive their test results via a personal online account (33\%), ordinary mail (30\%), e-mail (20\%) or personal communication (3\%); not specified in the rest (23\%). Only three companies (10\%) required the results to be sent to the consumer's general practitioner, although $84 \%$ encouraged consumers to contact their physician if they had any questions or concerns about their health status or interpretation of the results. Fifty percent of the websites offered pre- and/or post-test counselling. Counselling was performed mainly by telephone (60\%) and e-mail (13\%); unspecified in the rest (27\%). The service was performed without an additional fee for consumers by 11 companies (73\%), with a fee in 3 (20\%) and unspecified in one (7\%).

Only 9 websites (30\%) mentioned specific risks relating to testing. In particular, genetic discrimination in 5 websites, potential for emotional and psychological effects in 6 , legal, familial or financial implications in 4 and false reassurance in 2.

Patient empowerment was the most frequently used selling argument (70\%), framed in sentences including: a. taking care of yourself now is vital; b. past generations don't have an advantage like this - we are really fortunate; c. your doctor could be sure of giving you the best treatment measurement; d. you are responsible for your health and one and only one life; e. you can predict your body health; f. knowing factors like your possible inherited disease susceptibility is something you want to know; g. you can stop feeling the uncomfortable fear about making your own health-related decisions; h. protect yourself now; i. the right knowledge about your inherited genes, j. you want to be sure you are doing everything you can to stay healthy; k. you want to be able to work well with your doctor and take the guesswork out of it.
Other selling arguments were: the availability of a registered and fully accredited clinical laboratory (37\%), assurance of confidentiality (33\%), short time for testing process and despatch of the results (30\%), special offer (20\%) and positive experience from customers (20\%).

\section{Discussion}

In recent years, the range of companies involved in the DTC genetic test market has been growing in parallel with the public interest in DTC genetic testing. ${ }^{8,9}$ But what kind of knowledge are these websites offering to consumers?

They emphasize acquiring knowledge of the risks. The main purpose of testing declared by the companies is to get an overall picture of the personal health risk via a genetic profile, allowing preventive measures to be taken. The majority of websites declared that genetic test results

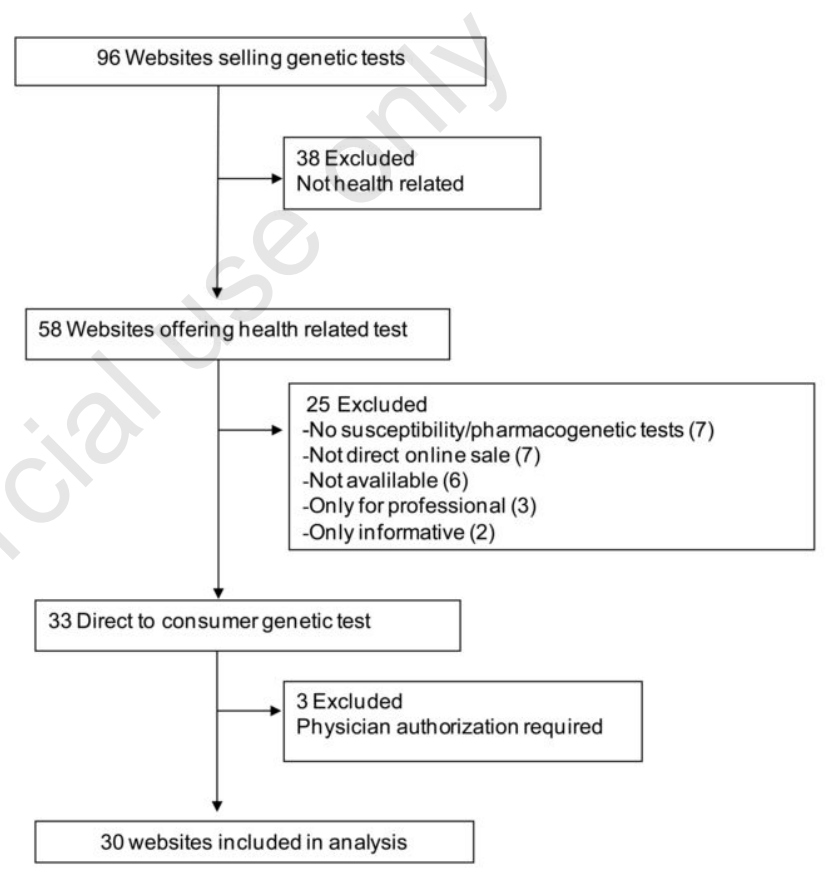

Figure 1. Criteria of websites selection.

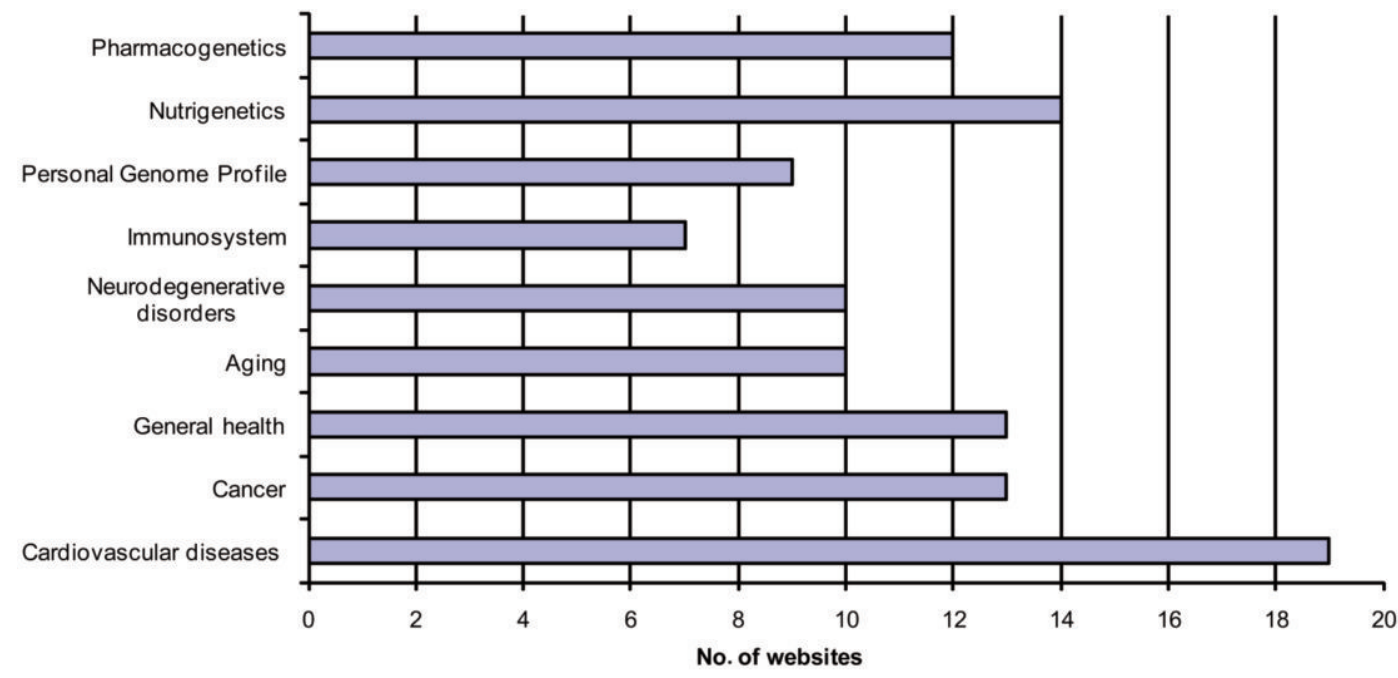


give an estimate of the predictive risk of disease or response to a drug; however, companies rarely required a physical health examination or completion of a health and lifestyle questionnaire prior to purchase of the test and only half of them offered a counselling service. Risk assessment based on genetic profile is correct when genetic predisposition is the only risk factor for a disease. When talking about a common disorder, lifestyle and environmental factors should be taken into consideration. ${ }^{10,11}$ Any test results could therefore be misleading since the estimated risk may be accurate on average, but very inaccurate for an individual. ${ }^{12}$ The evidence is that, although many of the assessed websites mentioned the role of the environment on disease risk, they still gave more emphasis to the role of genetics. One of the websites, for example, reports the influence of environment versus genes for each common disease tested for, but the first statement that a consumer reads when visiting the health page is: Your disease risk is impacted by your genetics. ${ }^{13}$ Still, this is not the whole story.

Genome-based prediction of common diseases is still not informative, with little predictive power, despite increasing developments in genomic research. ${ }^{14}$ There are as yet no common criteria for establishing which genetic markers should be used for assessing the risk for a particular disease. It is therefore not surprising that there are differences in the results given by different companies for the same genetic test; ${ }^{15}$ and the primary source of discrepancy in disease-risk prediction across companies was the variation in the selection of genetic markers.

Information and empowerment are not directly proportional. But when the information is incomplete, as in the case of the websites analysed in this study, either the person is competent in assessing its meaning or implication, or the risk of generating wrong knowledge is high. In this context the emphasis on genetic profile's role in the development of a disease could lead people to abandon all preventive measures - such as stopping smoking and losing weight - that have proven successful and are likely to be broadly beneficial in relation to many diseases. Alternatively an adoption of an unnecessary preventive measure could be also possible in a case of a false positive test result.

A study by McGuire et al. ${ }^{16}$ on social networkers' attitude toward direct-to-consumer personal genome testing led to important findings that are worth presenting here. Despite the fact that the average website denies the diagnostic power of its tests, $38 \%$ of respondents $(\mathrm{n}=1087)$ who would consider using personal genome testing interpreted the results as a medical diagnosis. Of those, $60 \%$ who actually used the website still considered the results to be a medical diagnosis. They also anticipated that this testing would influence their future healthcare decisions. Fifty-three percent of the respondents declared that personal genomic testing increases individuals' control over their health and $74 \%$ would consider testing someone other than themselves. This result is consistent with data reported by C.S. Mott Children's Hospital showing that $53 \%{ }^{17}$ of the parents interviewed were interested in personal genetic testing for their children.

Perceived knowledge and the feeling of being empowered in terms of information assessment are, to a significant extent, directly proportional. Indeed, in the study by McGuire et al., $46 \%$ of the participants claimed to know enough about genetics to understand the results. Forty percent said they would use genetic testing to learn about their genetic make-up without having to go through a physician. ${ }^{16}$

Health communication strongly advocates the need to tailor information in order to present contents that match individuals' educational, psychological and cultural levels and their characteristics. Online selling companies still play on generic concepts which, being socially appealing, influence the formation of a positive attitude towards their products. Among these concepts, empowerment is a strong one. In the context of empowerment, the benefits of spreading health information seem to be negatively counter-balanced by the burden of critical thinking skills imposed on individuals who have to evaluate that informa- tion. If, in the last ten years, much institutional and academic effort has been made to highlight all the skills that an empowered consumer should have, it is probably time to start thinking how to build these skills in the public at large. Of course, this is a question that involves educational efforts beyond the healthcare context, and it is still very speculative in nature.

A paper published by Bowen et al. back in $2005^{18}$ argued in favour of better regulation of the marketing of genetic tests. It is difficult to control the virtual world of the internet and the types of website that appear there on a daily basis. Yet it is undoubtedly time to speak up about the side-effects of the instrumentalisation of the concept of empowerment, and to regulate at least its usage. We have, here, a concept that is still too vague and still insufficiently operational. Overall, we wonder if, where and how the term empowerment should be used in the current healthcare context, and we fear that until the myth of the relationship between health information and autonomous decisionmaking is alive these questions will not receive clear answers.

Correspondence: Dr. Loredana Covolo, Department of Applied and Experimental Medicine, Section of Hygiene, Epidemiology and Public Health, University of Brescia, viale Europa 11, 25123 Brescia, Italy.

Tel. +39.030 .3717697 - Fax: +39.030 .3717686 .

E-mail: covolo@med.unibs.it

Key words: genetic tests direct-to-consumer, internet, empowerment. Contributions: the article was conceived by all authors; SR, LC, article drafting; LC, web search and analysis; G0, UG, critical revision.

Conflict of interest: the authors declare no conflicts of interest.

Received for publication: 27 October 2011.

Accepted for publication: 21 November 2011.

(C) Copyright L. Covolo et al., 2011

Licensee PAGEPress, Italy

Journal of Public Health Research 2012; 1:e3

doi:10.4081/jphr.2012.e3

This work is licensed under a Creative Commons Attribution NonCommercial 3.0 License (CC BY-NC 3.0).

\section{References}

1. Anderson RM, Funnell MM. Patient empowerment: myths and misconceptions. Patient Edu Couns 2010;79:277-82.

2. Rubinelli S, Nakamoto K, Schulz PJ. Health literacy beyond knowledge and behaviour. Int J Public Health 2009;54:307-1.

3. Rubinelli S, Nakamoto K, Schulz PJ. The rabbit in the hat: dubious argumentation and the persuasive effects of Direct-To-Consumer Advertising of prescription medicines. Commun Med 2008;5:49-58.

4. Schulz PJ, Nakamoto K. Bad literacy, the internet, and the limits of patient empowerment. Artificial Intelligence and Health Communication, AAAI Press/ The MIT Press 2011:65-69.

5. Schulz P, Nakamoto K. Emerging Themes in Health Literacy. SComS 2006;5:1-10.

6. Nutbeam D. Health literacy as a public health goal: a challenge for contemporary health education and communication strategies into the 21st century. Health Promot Int 2000;15:259-67.

7. Riffe D, Lacy S, Fico FG. Analyzing Media Messages. Using quantitative content analysis in research. Mahwah, NJ, USA, Lawrence Erlbaum Associates, 1998.

8. Wilde A, Meiser B, Mitchell PB, Schofield PR. Public interest in predictive genetic testing, including direct-to-consumer testing, for susceptibility to major depression: preliminary findings. Eur J Hum 
Genet 2010;18:47-51.

9. Gollust SE, Wilfond BS, Hull SC. Direct-to-consumer sales of genetic services on the internet. Genet Med 2003;5:332-7.

10. Vineis P, Schulte P, McMichael AJ. Misconceptions about the use of genetic tests in populations. Lancet 2001;357:709-12.

11. Melzer D, Hogarth S, Liddell K, et al. Genetic tests for common diseases; new insights, old concerns. BMJ 2008;336:590-3.

12. Welch HG, Burke W. Uncertainties in genetic testing for chronic disease. JAMA 1998;280:1525-1527.

13. 23andMe [Internet]. Available from: https://www.23andme.com/ health/risks/. Accessed on: June 2011.

14. Janssens AC, van Duijn CM. Genome-based prediction of common diseases: methodological considerations for future research.
Genome Med 2009;1:20.

15. Ng CP, Murray SS, Levy S, Venter JC. An agenda for personalized medicine. Nature 2009;461:724-6.

16. McGuire AL, Diaz CM, Wang T, Hilsenbeck SG. Social networkers' attitudes toward direct-to-consumer personal genome testing. Am J Bioethics 2009;9:3-10.

17. C.S. Mott Children's Hospital National Poll on Children's Health. Most Parents Interested in At-Home Personal Genetic Testing for Their Kids, 2010. Available from: http://www.med.umich.edu/ mott/npch/pdf/081610report.pdf

18. Bowen DJ, Battuello KM, Raats M. Marketing genetic tests: empowerment or snake oil? Health Educ Behav 2005;32:676-85. 